\title{
A formulação de um conceito operacional em educação ambiental a partir de um contexto de múltiplas de abordagens
}

\author{
leda Maria Duval de Freitas ${ }^{1}$
}

\begin{abstract}
RESUMO: O presente artigo busca, a partir de uma imersão na literatura que trata da Educação Ambiental e que se caracteriza pela multiplicidade de abordagens que envolve o tema, delinear um conceito de Educação Ambiental, mas resguardando-se, no entanto, no sentido de qualificá-lo como operacional, tendo em vista que constituiu-se como referência para uma pesquisa que investigou, no contexto dos chamados novos movimentos sociais, uma experiência ecocomunitária de matriz libertária: o projeto Eco-Comunidad del Sur (Eco-Sur). Essencialmente teórico-conceitual, usa como aporte a bibliografia especializada disponível e recorrente na área até o ano de 2003.
\end{abstract}

Palavras-chave: educação ambiental; múltiplas abordagens; Comunidad del Sur; conceito operacional.

“(...) a educação ambiental deve ser entendida como educação política, no sentido de que ela reivindica e prepara os cidadãos para exigir justiça social, cidadania nacional e planetária, autogestão e ética nas relações sociais e com a natureza (...) a educação ambiental como educação política enfatiza antes a questão 'por que' fazer do que 'como' fazer."

Marcos Reigota

\section{INTRODUÇÃO}

A formulação de um tema de pesquisa envolve a exata delimitação do objeto que se pretende estudar. No cumprimento desta exigência durante o desenvolvimento da pesquisa de Mestrado $^{2}$, e em função da multiplicidade de $\square$ abordagens associadas à Educação Ambiental, procedemos à especificação do significado a ela atribuído no contexto da investigação que desenvolvíamos e a qualificamos como recurso ou estratégia operacional, de trabalho.

Como buscamos subsídios para uma reflexão no teor das diferentes perspectivas teórico-metodológicas que orientam a Educação Ambiental, a tarefa implicou numa revisão da literatura especializada, notadamente em relação à produção recorrente e disponível entre 2001 e 2003, a partir da qual foi possível identificar alguns dos seus pressupostos e na medida em que historicamente o conceito foi se constituindo.

Assim, em função do processo de revisão de literatura realizado, entendemos ser oportuno compartilhar o exercício desenvolvido no âmbito da mencionada pesquisa, podendo se constituir mesmo numa eventual referência ao debate teórico-conceitual sobre o campo da Educação Ambiental.

1 Mestre em Educação Ambiental pelo Programa de Pós-Graduação em Educação Ambiental da Universidade Federal de Rio Grande. Professora da Rede de Ensino do Estado do Rio Grande do Sul e da Rede de Ensino do Município do Rio Grande (RS). Integra a equipe do Programa de Educação Ambiental do Porto do Rio Grande.

2 A utopia compartida e o compartir da utopia: A Educação Ambiental no contexto de uma experiência ecológica integral: a Eco-comunidad del Sur. Rio Grande, 2003. 211 f. Dissertação (Mestrado em Educação Ambiental) - Universidade Federal do Rio Grande, Rio Grande, 2003. 


\section{A CONSTRUÇÃO DO CONCEITO: ORIGENS, RECORRÊNCIAS E INOVAÇÕES}

Nas linhas que seguem, nos lançamos à tarefa de apontarmos como a Educação Ambiental foi se constituindo enquanto movimento, procurando evidenciar o entrelaçamento do mote com os diferentes âmbitos em que se desenvolve (espaços escolares ou em organizações não governamentais, grupos ecológicos, agrupamentos diversos e comunidades autônomas), bem como buscando evidenciar o espectro conceitual que encerra, os princípios inspiradores e os seus eixos fundamentais.

Uma primeira constatação se faz necessária. O campo da Educação Ambiental (EA) abriga uma grande diversidade de experiências e reflexões. É o que argumenta Luz María Neto Caraveo, coordenadora geral da Agenda Ambiental da UASLP (Universidad Autonoma de San Luis Potosí), do México, corroborada pelo que indica o exame atento da literatura especializada. Ainda segundo a pesquisadora, apesar da diversidade de abordagem em torno da Educação ambiental, é possível identificar confluências. E menciona duas possíveis:

"El primero es la expectativa de que la educación - en cualquiere de sus formas y espacios - puede ser una vía para la transformación de nuestra sociedad y nuestra cultura. El segundo es la entereza de suponer que las problemáticas ambientales, todavía, pueden solucionarse y hasta prevenirse." (2001, p. IX).

A diversidade e a confluência no campo da educação ambiental, no entanto, foi se desenhando na medida mesmo do seu processo de constituição: das origens, passando pela difusão e posterior consolidação.

É praticamente consenso que as grandes reuniões internacionais promovidas pela UNESCO e PNUMA, o "Clube de Roma" (1968), a "Conferência de Estocolmo" (1972), "Conferência de Belgrado" (1975), "Conferência de Tbilisi" (1977), "Conferência de Moscou" (1987), a "Eco-92", no Rio de Janeiro, a "Rio + 10”, ocorrida em 2002 na África do Sul, são marcos que passaram a atribuir significados e sentidos à Educação Ambiental. Porém, acreditamos ser possível encontrar os seus antecedentes alhures.

Este exercício nos leva a J. J. Rousseau, um dos precursores da metodologia naturalista, já que advogava por uma escola que fosse capaz de educar a criança sem a influência perniciosa da sociedade. Para este filósofo ilustrado, a concepção de "meio" é radicalmente naturalista, "no sólo con la idea de aprender de la naturaleza, sino más bien para adaptar la vida y evolución del niño a la propia vida y evolución natural: el hombre natural" (GÓMEZ, 2001, p. 327-328).

Rousseau vai reafirmando sua posição ao considerar a natureza como nosso primeiro mestre. Nas mãos de Deus, argumenta, tudo é perfeito, mas degenera nas mãos dos homens, e indica em seguida que a natureza deseja que as crianças sejam crianças antes de serem homens.

Um pouco mais tarde, entre o final do século XIX e início do XX, o movimento da Escola Nova igualmente reclama o contato das crianças com o "meio". Este movimento contrapõe a pedagogia do interesse do aluno à tradicional pedagogia do esforço do aluno, destacando a inutilidade dos saberes e valores que não correspondam às necessidades dos alunos. Nas suas premissas, a Escola Nova considera a natureza como um recurso educativo ${ }^{3}$.

$3 \quad$ Na transição do século XIX para o XX surgiram inúmeras escolas novas, sendo que a pioneira foi a de Abbotsholme, fundada em 1889, na Inglaterra, seguida de várias espalhadas pela França, Alemanha, Bélgica, Itália e Estados Unidos. Em função das diferentes tendências, em 1919 o Bureau Internacional das Escolas Novas, sediado em Genebra, aprova 30 itens considerados básicos da nova pedagogia, de modo que, para uma escola ser considerada pertencente ao movimento, deveria cumprir pelo menos dois terços deles. Segundo esse padrão, são as seguintes as principais características da escola nova: educação integral (intelectual, moral, física); educação ativa; educação prática. Sendo obrigatórios os trabalhos manuais; exercício de autonomia; vida no campo; internato; co-educação; ensino individualizado. 
Já no início da década de 1970, Freinet argumentava que o ensino de ciências deveria se basear exclusivamente na observação e na experiência infantil com o meio.

No exame de algumas obras, também podemos enxergar a emergência do conteúdo que entrelaça o homem e o ambiente. Nesse sentido, o livro de Thomas Huxley, Evidências sobre o lugar do homem na natureza (1863), é ilustrativo, pois trata das interdependências entre os seres humanos e os demais seres vivos. No mesmo caminho, George P. Marsh publica O Homem e a natureza (1864), que discute a ação do homem sobre os recursos naturais. A necessidade de uma ética de uso de recursos da terra foi tema de inúmeros artigos publicados em A Sand County Almanac, por Aldo Leopoldo em 1949. Já em 1962, é editado o livro Primavera Silenciosa, da jornalista Rachel Carson. O livro obteve uma grande repercussão no mundo todo, por tratar da perda de qualidade de vida em função da cultura do uso dos produtos químicos e dos seus efeitos sobre os recursos ambientais.

Se, por um lado, podemos situar nestas ideias, em certa medida, as origens ou os indícios mais remotos de uma Educação Ambiental, por outro, podemos evocar eventos e/ ou circunstâncias mais recentes como elementos desencadeadores que influenciaram no surgimento mesmo de um movimento de discussão e consolidação deste mote.

Todo aquele movimento de contestação da década de 1960 pode ser considerado um ponto de arranque: vida alternativa, desencanto com as cidades e tentativas de reconstruir a vida no campo; as comunidades alternativas rurais. Mesmo as experiências que se relacionavam com itinerários e atividades na natureza, saídas de campo, etc., levadas a cabo por grupos de educadores inovadores que, em diferentes países, conquistaram o respaldo institucional para tais atividades. Na Inglaterra, por exemplo, foi criado o Council for Environmental Education, órgão que passou a coordenar essas múltiplas atividades. Igualmente, ocorria o crescimento da consciência da degradação ambiental. A gravidade desses problemas ambientais passa a constituir-se em tema de interesse acadêmico, e diferentes áreas do conhecimento passam a reivindicar sua tradição ecológica. Pela mesma época, na Suécia se iniciava uma revisão de programas escolares baseada na ideia de que o tema ambiental devia ser um aspecto importante das diferentes disciplinas e um ponto de confluência entre elas. A França, que já tinha uma ampla tradição didática no trabalho com o entorno, também vai incorporar nela o enfoque ecológico.

Nesta altura, portanto, já se esboçava, principalmente no continente europeu, uma concepção sobre EA, entendida não como uma nova disciplina, mas como uma progressiva integração da questão ambiental a traspassar todo o currículo escolar. Esta noção estava afinada com as concepções nórdicas, que a viam como uma "dimensão". María Carmen Gonzáles Muñoz, no artigo "Principales tendencias de la Educación Ambiental en el sistema escolar", comenta que este sentido então atribuído a EA apontava na direção de enfocar "el medio ambiente tanto en sus aspectos físicos como sociales, culturales, económicos etc. Se recomienda también que el estudio medio empiece en el entorno immediato" (1996, p.18).

Mas são as reuniões organizadas por distintas organizações internacionais, e os relatórios/declarações que produzem, que vão marcar a consolidação e difusão do tema Educação Ambiental.

Em 1968 teve lugar, em Roma, uma reunião de renomados cientistas dos países desenvolvidos, de diferentes áreas do conhecimento, com o fim de discutir consumo, reservas de recursos não renováveis e o crescimento demográfico mundial até meados do século XXI. Estava fundado o Clube de Roma. O resultado desta reunião indicou a necessidade urgente de conservação dos recursos naturais, controle do crescimento populacional e investimento "numa mudança radical na mentalidade de consumo e procriação” (REIGOTA, 2001, p.23).

O "Clube de Roma" conseguiu gerar um outro resultado e um produto interessante. No primeiro caso, alçou o problema ambiental em nível planetário. No segundo, publicou

Revbea, Rio Grande, 7: 80-91, 2012. 
em 1972 o relatório The Limits of Growth ${ }^{4}$, que acabou se constituindo numa referência internacional a elaboração de políticas e projetos.

Esta reunião internacional, mesmo que não tenha avançado no debate sobre a $E A$, influenciou consideravelmente na organização de um outro encontro, "A Primeira Conferência Mundial de Meio Ambiente Humano", ocorrida em Estocolmo, realizado em 1972 sob os auspícios da Organização das Nações Unidas (ONU/UNESCO), que tratou a questão mais diretamente.

O evento é tido como um marco político internacional para a emergência de políticas de gerenciamento ambiental. Produziu a Declaração sobre o Ambiente Humano; estabeleceu o Plano de Ação Mundial com o objetivo de inspirar e orientar a humanidade para a preservação e melhoria do meio ambiente; reconheceu o desenvolvimento da Educação Ambiental como elemento crítico para o combate à crise ambiental no mundo; enfatizou a urgência da necessidade do homem reordenar suas prioridades (DIAS, 1998). Oficialmente, parece residir aí o nascimento da EA. Delineava-se a ideia de que a solução dos problemas ambientais passaria pela educação do cidadão. Desenhava-se o princípio da Educação como base da política ambiental, agora com a força de uma diretriz internacional. Os princípios que nela se definem são claros a este respeito:

"Es indispensable una labor de Educación en cuestiones ambientales, dirigida tanto a las generaciones jóvenes como a los adultos y que preste la debida atención al sector de población menos privilegiado, para ensanchar las bases de una opinión pública bien informada y de una conducta de los indivíduos, de las empresas y de las colectividades, inspirada en el sentido de su responsabilidad en cuanto a la protección y mejoramiento del medio en toda su dimensión humana." (PRINCÍPIO 19 apud MUÑOZ, 1996, p. 18).

Em síntese, na década de 1970 não só o conceito de EA vai sendo constituído como uma "dimensão", como também a noção de meio ambiente se amplia, passando a ser associado ao meio natural e, ao mesmo tempo, incorporando os aspectos sociais. Para além desta perspectiva, também se verificou nesta década o delineamento da Educação Ambiental como um movimento ético, somando-o àqueles outros já ressaltados, 0 aspecto social ou econômico, deslocando-se assim de uma noção simplista vinculada ao conservacionismo para algo muito mais complexo.

Já correndo o ano de 1973 foi criado um órgão vinculado a ONU/UNESCO, o PNUMA (Programa das Nações Unidas para o Meio Ambiente), como instrumento de coordenação entre organismos nacionais e internacionais, o que acabou implicando num novo impulso a Educação Ambiental.

Em 1975 volta a acontecer uma nova reunião internacional, o Encontro de Belgrado (lugoslávia), como ficou conhecido. Foi neste evento que ocorreu o lançamento do Programa Internacional de Educação Ambiental (PIEA), que expressava o propósito de promover a EA em todos os níveis da educação, fixando metas e objetivos, delimitando o seu âmbito e conteúdos. Depois de Belgrado, seguiu-se uma série de outros encontros regionais em todo o mundo, inclusive na América Latina.

A Primeira Conferência Inter-Governamental de Educação Ambiental de Tbilissi ocorre em função das recomendações da reunião anterior. Também promovida pela UNESCO/ PNUMA, realizou-se em 1977, na cidade de Tbilissi - Georgia. Desta conferência resultou

$4 \quad$ O título do Relatório em português recebeu a seguinte chamada: Os Limites do Crescimento. Não manuseamos o documento original, mas através do trabalho de Mesarovic \& Pestel, denominado Momento de Decisão: O Segundo Informe ao Clube de Roma. Rio de Janeiro: Agir, 1975. 246p. O Relatório estabelecia modelos globais baseados nas técnicas pioneiras de análise de sistemas, projetados para predizer como seria o futuro se não houvesse modificações ou ajustamentos nos modelos de desenvolvimento econômico adotados. O documento denunciava a busca incessante do crescimento da sociedade a qualquer custo, e a meta de se tornar cada vez maior, mais rica e poderosa, sem levar em conta o custo final desse crescimento. Os modelos demonstraram que o crescente consumo geral levaria a humanidade a um limite de crescimento, possivelmente a um colapso. Os políticos rejeitaram as observações. Entretanto, o livro atingiu, em parte, seu objetivo: avisar os homens da necessidade de maior prudência nos nossos estilos de desenvolvimento. 
um importante documento, a Declaração sobre Educação Ambiental, que estabelecia pautas de atuação e prioridades para o futuro. Genebaldo Freire Dias (1998) detalha o referido documento:

"Documento técnico que apresentava as finalidades, objetivos, princípios orientadores e estratégias para o desenvolvimento da EA e elegia o treinamento de pessoal, o desenvolvimento de materiais educativos, a pesquisa de novos métodos, o processamento de dados e a disseminação de informações como o mais urgente dentro das estratégias de desenvolvimento." (1998, p.22).

Os anos que se seguiram a este evento em Tbilissi, foram fundamentais para a Educação Ambiental. De uma vaga aspiração passa a tomar forma de um corpo teórico sólido e dotado de uma estratégia rigorosa e com caráter institucional. E foi naquele período que tiveram lugar um conjunto de situações e iniciativas que vão consolidando a EA. Uma das mais significativas, sem dúvida, no marco do PIEA, foi a Reunião Internacional de Especialistas que ocorreu em Paris em 1982.

A década de 1980 avança e nela se verifica o agravamento e generalização da crise ambiental, assim como se amplia a preocupação com o problema. Seu caráter global fica escancarado, enfatizando-se ao mesmo tempo as questões relacionadas com a desigualdade mundial e com os desequilíbrios Norte-Sul. A EA responderá a esses desafios acentuando o caráter sistêmico de suas propostas, assinalando a importância das inter-relações entre os problemas e, portanto, enraizando ainda mais o seu caráter de "dimensão".

Entre o final da década de 1980 e a primeira metade da seguinte, a EA passa a ser vinculada com o conceito de desenvolvimento sustentável.

Este conceito emerge com os trabalhos da Comissão Brundtland (Comissão Mundial de Meio Ambiente e de Desenvolvimento, 1983), agregada às Nações Unidas, coordenada pela primeira ministra norueguesa, Gro Harlem Brundtland. A comissão de especialistas realiza, durante vários anos, reuniões itinerantes em várias cidades do mundo discutindo os problemas ambientais e suas implicações.

Os resultados desse conjunto de debates foram publicados no famoso livro O Nosso Futuro Comum (1987), que realiza propostas para o futuro. relatório:

Na avaliação de María Carmem Gonzáles Muñoz, (1996) o conteúdo deste verdadeiro

"(...) avanza sobre el concepto de "ecodesarrollo" para defini el de 'desarrollo sostenible' como aquel que satisface las necesidades de las actuales generaciones sin comprometer las de las futuras, atendiendo a equilíbrio social y ecológico y prioritariamente a las necesidades de los más pobres." (1996, p.26).

No Segundo Congresso de Educação Ambiental ocorrido em Moscou, em 1987, os trabalhos se organizam em torno aos elementos decisivos da EA: informação, investigação e experimentação de conteúdos e métodos, formação de pessoal e cooperação regional e internacional, questões estas concebidas no seu conjunto e não como ações isoladas.

Esta reunião de Moscou avançou na mesma linha do relatório da Comissão Brundtland, destacando a inutilidade de uma Educação Ambiental que não colocasse ênfase sobre a realidade mundial desigual e que não alcance a todos os coletivos sociais. Os conceitos de necessidades, limitações, descentralização, equidade, participação e outros mais, começaram a se generalizar na EA.

Para sermos mais precisos, apontamos abaixo, a definição e princípio que emerge do Congresso de Moscou, segundo Munoz (1996): 
“(...) La E.A. se concibe como un processo permanente en el que los individuos y la colectividad cobran conciencia de su medio y adquieren los conocimientos, los valores, las competencias, la experiencia y la voluntad capaces de hacerlos actuar individual y colectivamente para resolver los problemas actuales y futuros del medio ambiente." (p. 28).

A reunião internacional do Rio de Janeiro, mais conhecida como Eco-92, igualmente dedicou atenção ao tema da Educação Ambiental, mas colocada numa relação com o desenvolvimento sustentável.

No manifesto produzido, considera-se a EA indispensável na modificação de atitudes e para desenvolver comportamentos compatíveis com o desenvolvimento sustentável, e estimula sua introdução em todos os níveis escolares.

O encontro paralelo à reunião oficial da Eco-92, como o Fórum Global (promovido por ONG's), igualmente ressaltou a importância da Educação Ambiental como estratégia básica para a urgente adoção individual e coletiva de novas atitudes e comportamentos ambientais.

Esta conferência paralela, em sua declaração de princípios, afirma que a EA:

“(...) es um proceso de aprendizaje permanente, basado en el respeto a todas las formas de vida (...) tal educación afirma valores y acciones que contribuyen a la transformación humana y social y a la preservación ecológica. Ella estimula la formación de sociedades socialmente justas y ecológicamente equilibradas, que conservem entre sí una relación de interdependencia y diversidad." (MUÑOZ, 1996, p. 27).

Naquele momento, a EA é marcada por elementos como a necessidade da responsabilidade individual e coletiva, o pensamento crítico, inovador e pela visão interdisciplinar que a caracteriza, assim como a consciência ética que deve suscitar. Mas a inovação explícita mais importante situa-se no intento de defini-la como uma Educação que: "no es neutra sino ideológica. Es un acto político, basado en valores para la transformación social" (Ibid.).

O alargamento da noção de EA vai se costurando no referido manifesto (Tratado de Educação Ambiental para Sociedades Sustentáveis e Responsabilidade Global), à medida que se atribui a ela a necessidade de tratar questões globais críticas, suas causa e inter-relações numa perspectiva sistêmica, inserida em seu contexto social e histórico, envolvendo aspectos primordiais como população, paz, direitos humanos, democracia, saúde, fome, degradação da flora e fauna.

Noutro sentido, a EA deveria capacitar as pessoas a trabalhar conflitos e a integrar conhecimento, aptidões, valores, atitudes e ações, buscando a transformação de hábitos consumistas e condutas ambientais inadequadas. Essas características sintetizam, em última instância, uma Educação para a mudança.

Neste ponto, acreditamos já ter oferecido subsídios para evidenciar o processo de emergência, desenvolvimento e evolução do mote Educação Ambiental, e mesmo para mostrar os postulados que passam a ser considerados na constituição do seu campo conceitual. Intentaremos, nas linhas que seguem, avançar na direção de agregar outras definições e/ou experiências possíveis para, a partir desses aportes, delinearmos o conceito no contexto da investigação que realizamos sobre a experiência da Eco-comuniad del Sur.

Retomando as definições apresentadas no Congresso de Moscou, apontadas anteriormente, podemos encaminhar uma ilação no sentido de que a E.A. se trata de um processo que afeta os indivíduos não só na etapa da Educação Formal e, neste caso, expressando uma clara inclinação em direção as atitudes e aos comportamentos, mas que 
deve assentar-se também na aquisição de uma série de conhecimentos e competências, que já haviam sido definidos desde 1975, no seminário ocorrido em Belgrado, e ratificado posteriormente em Tbilisi. Esses conhecimentos e competências estavam estruturados assim:

\section{Consciência}

Ajudar as pessoas e aos grupos sociais a adquirirem maior sensibilidade e consciência do meio ambiente em geral e dos problemas conexos.

\section{Conhecimentos}

Ajudar as pessoas e aos grupos sociais a adquirir uma compreensão básica do meio ambiente em sua totalidade, dos problemas conexos e da presença e função da humanidade, o que inclui uma responsabilidade crítica.

\section{Atitudes}

Ajudar as pessoas e aos grupos sociais a adquirir valores sociais e um profundo interesse pelo meio ambiente, que os impulsione a participar ativamente na sua proteção e melhoramento.

\section{Aptidão}

Ajudar as pessoas e aos grupos sociais a adquirir as aptidões necessárias para resolver problemas ambientais.

\section{Capacidade de Evolução}

Ajudar as pessoas e aos grupos sociais a avaliarem as medidas e os programas de Educação Ambiental em função dos fatores ecológicos, políticos, econômicos, sociais, estéticos e educacionais.

\section{Participação}

Ajudar as pessoas e aos grupos sociais a desenvolverem seu sentido de responsabilidade e a tomarem consciência da urgente necessidade de prestar atenção aos problemas do meio ambiente, para assegurar a adoção de medidas adequadas a respeito.

Fonte: MUÑOZ, María Carmen González. Principales tendencias y modelos de la Educacón Ambiental en el sistema escolar. In: Revista Ibero Americana de Educación. Madrid: OEI, $n^{0}$ 11, mai.-ago 1996. p.29. (Tradução nossa) 
Comesses dados, podemos também inferir quea proposta de uma EducaçãoAmbiental construída até este momento, não passava simplesmente pela ideia de natureza como um recurso didático (educativo), usando o meio ambiente para proporcionar informação geográfica, científica, etc, mas a de ensinar a partir da natureza, senão a de educar para a natureza, com possibilidade de enfrentar os problemas gerados na relação homem-meio, de educar sobre o papel do ser humano na biosfera.

Os princípios indicados, portanto, leva-nos a pensar numa Educação Ambiental ao mesmo tempo assentada no desenvolvimento sustentável e na transformação dos modelos econômicos. E neste contexto, a Educação Ambiental não pode se situar somente no mundo escolar, mas refere-se também a educação dos adultos, de gestores, de políticos, de mulheres, associações, comunidades, enfim, a todos. Mas como os setores sociais estão inseridos de formas distintas nos problemas ambientais, por consequência, a EA também os afetará de maneira diversificada. Os pontos de partida, por certo, serão os setores mais suscetíveis ao debate ambiental e aos benefícios de uma proposta de sociedade sustentável.

Nesta perspectiva, então, a EA pode ser entendida como uma educação aberta, que ultrapasse os limites da educação formal e institucional, alcançando toda a população. O seu conteúdo refere-se, a rigor, ao âmbito das relações natureza-sociedade e ao equacionamento dos problemas que emergem desta relação.

Esses argumentos, considerados em conjunto, nos levam a buscar uma definição de Educação Ambiental onde os mesmos estejam assentados. Na proposta de definição de Novo (1996), aparecem com contornos bem marcados:

"El proceso que consiste en acercar a las personas a una comprensión global del medio ambiente (como un sistema de relaciones múltiples) para elucidar valores y desarrollar actitudes y aptitudes que les permitan adoptar una posición crítica y participativa respecto de las cuestiones relacionadas con la conservación y correcta utilización de los recursos y la calidad de vida." (NOVO, 1996, p.30).

A despeito do nosso reconhecimento em relação a este conceito que, de certa forma, sintetiza e agrega a experiência de constituição do campo da educação ambiental nessas últimas décadas, interessa-nos ainda buscar ampliá-lo em outras dimensões, considerando de maneira mais clara, aspectos que apontem na direção da transformação social. E o Manual Latino Americano de Educação Ambiental, publicado em 1994, e elaborado já a partir de um suporte de amplas discussões realizadas mundo á fora, sugere essa perspectiva mais abrangente. Vejamos:

"Educação ambiental é, na verdade, uma proposta de filosofia de vida, que resgata valores éticos, estéticos, democráticos e humanistas. Ela parte de um princípio de respeito pela diversidade natural e cultural, que inclui a especificidade de classe, de etnia e de gênero. Por isso, uma de suas características é a defesa da descentralização em todos os níveis e a distribuição social do poder, reconhecendo também como formas de poder, o acesso à informação e ao conhecimento. A educação que queremos visa modificar as relações entre a sociedade e a natureza em função da melhoria da qualidade de vida, como esta é percebida pelas comunidades. Ela propõe a transformação do sistema produtivo e do consumismo em uma sociedade baseada na solidariedade, afetividade e cooperação, visando a justa distribuição de seus frutos entre todos. Uma educação holística propõe a busca de novos valores e práticas, baseados em uma postura ética que, aliados à sabedoria acumulada pela humanidade e aos conhecimentos científicos, perpassem todas as ações das comunidades, de órgãos governamentais, partidos políticos e de ONG's. É também uma educação democrática que propicia oportunidades para que as pessoas

Revbea, Rio Grande, 7: 80-91, 2012. 
e grupos desenvolvam sua criatividade, reaprendendo o mundo, sem estabelecer separações artificiais entre mestres e aprendizes, entre sexos e idades, e entre saberes." (VIEZZER; OVALLES, 1994, p. 20-21).

Uma outra definição de Educação Ambiental se impõe nos quadros dos significados que buscamos lhe atribuir: é aquela permeada pela noção da questão ambiental e da EA como um novo campo de ação político-pedagógico.

Este viés é abordado com muita propriedade por Carvalho (2000, p.58), argumentando que é na ação educativa orientada para o ambiental que se situa a possibilidade de uma educação ambiental cidadã, concebida como uma "intervenção político-pedagógica que tem como ideário a afirmação de uma sociedade de direitos, ambientalmente justa".

Segundo a autora, as múltiplas interpretações contemporâneas do ambiental suscitam ações e visões divergentes, inclusive nas esferas do Estado e do mercado. Diante deste quadro, argumenta que este campo é transformado em lugar de disputa entre concepções, interesses e grupos sociais. Como consequência desta multiplicidade, Carvalho (2000, p.59) diz que não se pode supor um amplo consenso, que permita uma reorientação consistente das relações da sociedade com a natureza, preferindo pensar "essa heterogeneidade de práticas e sentidos", em torno do ambiental como um campo social instável, contraditório e multifacetado, que constitui um amplo e diversificado ideário ambiental. E neste campo podem ser incluídos, complementa, movimentos sociais de posturas ideológicas diferenciadas, políticas públicas, partidos políticos, estilos de vida alternativos, opções e hábitos de consumo, entre inúmeras possibilidades. E o sentido da ação do educador ambiental, na análise da autora, se constitui neste pantanoso terreno, posicionando-se como educador (a) e como cidadão (ã). Neste envolvimento, portanto, gera-se o caráter pedagógico e político de sua intervenção.

A questão ambiental agrega conteúdo político, na abordagem da autora, quando se estabelecem lutas sociais em torno do acesso e formas de uso dos bens ambientais. Os conflitos realçariam a condição pública dos bens ambientais ante as investidas dos interesses privados sobre o patrimônio natural. Assim, ela encara esses conflitos enquanto uma luta por cidadania na medida em que a reivindicação que se faz é pelo caráter público do meio ambiente.

Carvalho enfatiza que a questão ambiental é alçada na esfera política (esfera pública das decisões comuns) quando a problemática do meio é entendida como fenômeno socioambiental. E a dimensão pedagógica das lutas ambientais ocorre quando:

“(...) instituem espaços efetivos de questionamento, encontro, confronto, e negociação entre projetos políticos, universos culturais e interesses sociais diferentes (...) estas lutas, tanto quanto toda educação ambiental orientada para a cidadania, podem contribuir de uma forma muito concreta para o avanço de um dos grandes desafios contemporâneos: a busca de possíveis novas tecituras entre a natureza e a política." (2000, p.61).

A análise de Isabel Carvalho envereda ainda pelo debate sobre a tensão entre a ampliação e/ou redução da esfera pública (entendida enquanto esfera política) e, adiante, acaba afirmando que nos quadros da atual cultura política ambientalista multifacetada ideologicamente, a vertente que prega a defesa dos valores emancipatórios é, hoje, uma força entre outras, em vias mesmo de enfraquecimento, o que acaba resultando em práticas de educação ambiental de tendência individualista e comportamental.

Num contexto, portanto, de um cenário político-cultural complexo, onde a força da crítica emancipatória - que se opõe ao status quo socioambiental - tende a ser amenizada, Isabel Carvalho aponta para uma Educação Ambiental "sensível às lutas socioambientais e pautada pela conquista da cidadania", pois "(...) representaria um espaço promissor na busca de uma sociedade justa e ambientalmente sustentável, integrando as forças emancipatórias (...)" com a potencialidade de manter "(...) o projeto de uma cidadania democrática" (Ibid., p. 64). 
Nesta altura, acreditamos que outra ilação foi se construindo naturalmente ao longo deste texto: a ideia de que a Educação Ambiental pode se constituir, na verdade, em todos os espaços que educam o cidadão e a cidadã. A literatura especializada trata desse assunto a partir da explicitação do conceito de Educação Ambiental Formal, Informal e Não Formal, ou seja, das escolas aos parques e reservas ecológicos, nas agremiações, associações de bairro, grupos minoritários, sindicatos, ONG's, universidades, meios de comunicação, comunidades alternativas, etc. Cada um desses espaços, pela sua constituição própria, peculiar, apresentam particularidades que irão refletir no formato e conteúdo da mesma.

É necessário dizer que a Educação Formal, vinculada ao âmbito escolar, é uma das que mais tem merecido a atenção de pesquisadores, gerando uma gama bastante variada de publicações (livros, artigos, etc.) e já considerável produção acadêmica (dissertações e teses).

Agora, impõe-se a necessária tarefa de exercitamos a síntese, buscando recuperar os aspectos abordados até aqui, para tornar possível a explicitação dos eixos que orientam a concepção de Educação Ambiental no âmbito deste trabalho. Então vamos lá:

a) procuramos traçar um roteiro sobre a evolução, desenvolvimento e consolidação do movimento que denominamos de Educação Ambiental. Consideramos, particularmente, as três últimas décadas e buscamos, a grosso modo, identificar suas origens mais remotas;

b) no seu momento inicial, ficou evidente a orientação conservacionista do movimento, em função principalmente da ampla tradição conservacionista dos países anglo-saxões, onde inicia seu desenvolvimento;

c) igualmente em suas origens, apresenta-se como característica do movimento, um desenvolvimento a partir de bases educativas, isto é, com professores que passam a desenvolver trabalho de campo, o que envolvia atividades sobre o meio, conservação da natureza, estudos sobre o entorno, etc;

d) a ideia da EA vai se desenvolvendo, ao mesmo tempo, no âmbito não formal, principalmente entre grupos de ecologistas, ainda escassos naquele momento, mas muito ativos;

e) na década de 1970, principalmente, o movimento foi se enraizando em grupos mais avançados e conscientes. O avanço conceitual se configurava na medida mesmo que a experiência progredia;

f) a ampliação do conceito de meio ambiente exigiu muito debate. Transitou de uma noção associada quase que exclusivamente ao meio natural, passando a abranger também os aspectos sociais;

g) no âmbito educativo formal, desenvolveu-se a concepção de que a EA teria que ser uma dimensão que traspassasse todo o currículo;

h) superando a noção do simples conservadorismo, a Educação Ambiental passou a ser entendida também como um movimento ético;

i) no plano da EA não formal, os grupos ecologistas somam as suas experiências, uma certa dimensão educativa, através de manifestos, conferências, sensibilizações;

j) no decênio 1980-1990 ocorreu um espraiamento da consciência sobre a problemática ambiental, indo dos grupos minoritários a sociedade em geral. Amplia-se e diversifica-se o movimento das ONG's;

k) amplia-se a crise socioambiental e se generaliza a noção de que a problemática ambiental é um fenômeno global;

I) os trabalhos da Comissão Brundtland apontam a necessidade imprescindívevelfid drasileria 
vincular os problemas ambientais com a economia internacional e com os modelos de desenvolvimento. Apresenta a proposta do desenvolvimento sustentável;

m) em 1987, com o Congresso de Moscou, decidiu-se que não é possível definir as finalidades da EA sem levar em conta as realidades econômicas, sociais e ecológicas de cada sociedade, bem como os objetivos que cada uma fixou para o seu desenvolvimento. Foi proposto que a EA alcance todos os coletivos sociais. Apontou-se ali que a escola e o que está fora da escola devem fundir-se para fazer EA.

n) a Conferência Mundial do Rio em 1992, através do Tratado de Educação Ambiental para sociedades sustentáveis e responsabilidade global, aposta na EA como um ato político baseado em valores para a transformação social;

o) a ampliação do debate e as experiências levadas a cabo ampliam o conceito de EA entendida enquanto uma proposta de filosofia de vida;

p) para além da perspectiva individualista e comportamental, esboça-se a proposta de uma Educação Ambiental pautada pela conquista da cidadania.

Agora, retomando uma das proposições iniciais relativas à necessidade de especificarmos operacionalmente, a partir das referências esboçadas ao longo deste texto, o significado de Educação Ambiental, e ratificando, através do exposto, uma multiplicidade conceitual de amplo espectro, processo este em permanente construção, avançamos agora na tarefa de delinear o conceito de EA que tomamos como referência na pesquisa que desenvolvemos no mestrado.

Designamos por Educação Ambiental um processo de educação permanente de intervenção político-pedagógica, podendo estar presente em todos os espaços que educam o cidadão e a cidadã, que objetiva a transformação, através de novas relações entre natureza e sociedade, na afirmação de uma sociedade de direitos, ambientalmente justa e sustentável.

\section{CONSIDERAÇÕES FINAIS}

A partir do conceito que esboçamos acima, delineado a partir do exame da multiplicidade de abordagens em torno do tema da Educação Ambiental, no foi possível constituir uma referência para examinar a experiência levada a termo pela Comunidad del Sur.

Com essa estratégia, conseguimos observar, a partir de um determinado momento da trajetória histórica do grupo, a construção de um projeto eco-comunitário alicerçado na tentativa de forjar um modelo alternativo e autogestionário de desenvolvimento, assentado num novo pacto com a natureza, na vivência de novos valores, na perspectiva da vida comunitária e do cooperativismo integral, nas relações solidárias, na espontaneidade e no coletivismo.

A prática da Educação Ambiental se concretizava, portanto, no contexto daquela ecocomunidade, na medida em que o grupo pauta sua experiência em valores éticos, estéticos, libertários e humanistas, respeitando a diversidade, descentralizando o poder, buscando a transformação do sistema produtivo e do consumo, estimulando a solidariedade, a afetividade, cooperação e desenvolvendo a criatividade e novas formas de sensibilidade.

Essas questões todas são pensadas e equacionadas no contexto de um processo permanente de construção, pelo diálogo, discussões e decisões coletivas, portanto numa situação de educação permanente, que é de intervenção política-pedagógica na medida em que envolve o grupo com os problemas do seu tempo, ao mesmo passo que procuram partilhar a experiência com outros grupos comunitários, associações de bairros, ONG's, cooperativas, redes, etc. 


\section{REFERÊNCIAS}

CARAVEO, Luz María Nieto. Apresentação. In: SANTOS, J.E.; SATO, Michèle. A contribuição da Educação Ambiental à esperança de Pandora. São Carlos: Rima, 2001. p.9-12.

CARVALHO, Isabel Cristina de Moura. A questão Ambiental e a emergência de um campo de ação político-pedagógica. In: LOUREIRO, C.; LAYRARGUES, P.; CASTRO, R. Sociedade e meio Ambiente: a Educação Ambiental em debate. São Paulo: Cortez, 2000. p. 53-65.

DIAS, Genebaldo F. Educação Ambiental: princípios e práticas. São Paulo: Global, 1998.

GÓMEZ, Javier García. Análise da Educação Ambiental na Espanha no contexto da União Euopéia. In: SANTOS, J. E.; SATO, Michèle. A contribuição da Educação Ambiental à esperança de Pandora. São Carlos: Rima, 2001.

MUÑOZ, Maria Carmem González. Principales tendencias y modelos de la Educación tal en el sistema escolar. In: Revista Ibero Amerocana de Educación: Educação Ambiental: teoría y práctica. n.11, p.13-74, mai/ago de 1996.

NOVO, María. La educación ambiental formal y no formal: dos sistemas complementarios. In: Revista Ibero Amerocana de Educación: educação ambiental: teoría y práctica. n. 11, p. 75-102, mai/ago., 1996.

REIGOTA, Marcos. O que é educação ambiental. São Paulo: Brasiliense, 2001.

VIEZZER, Moema L.; OVALLES, Omar. (Org.). Manual latino-americano de educação ambiental. São Paulo: Gaia, 1994. 